\title{
Effects of different stevia-to-onion ratios and heating temperatures on physicochemical and sensory attributes of onion-stevia hot water extracts
}

\author{
Hae-Il YANG ${ }^{1}$, Kashif AMEER ${ }^{1,2,3}$, Jong-Bang EUN ${ }^{1 \star ~(1) ~}$
}

\begin{abstract}
Increased consumption of artificial and intense natural sweeteners have led to serious health implications and safety issues for intended consumers. Among all natural sweeteners, steviol glycosides (SGs: stevioside \& rebaudioside-A) are popularly known as zero-caloric intense sweetening compounds of natural origin. Hot water extraction (HWE) is considered ecofriendly and less expensive, and HWE extracts are safe for human consumption as compared to organic solvents extraction. Onion (Allium cepa L.) and stevia (Stevia rebaudiana) were extracted using a single factor experimental approach to determine the optimal onion-stevia hot water extract (OSHE) extraction conditions. Physicochemical and sensory attributes of onion hot water extract (OHE) and OSHE extracted at varying stevia-to-onion ratios and temperatures were investigated. The results showed that total phenolic content (TPC) increased and total flavonoid content (TFC), $L^{*}, a^{*}$ and $b^{*}$ values decreased with corresponding increases in stevia-to-onion ratio and extraction temperature. In contrast, total soluble solids increased with increase in onion-stevia ratio, whereas $\mathrm{pH}$ values declined with increasing temperature. Glucose was the most dominant organic sugar in OSHE followed by sucrose and fructose. In conclusion, OSHE obtained at $115^{\circ} \mathrm{C}$ and 1:100 stevia-to-onion ratio (w/w) could be produced as a natural sweetener after concentration or drying and could be exploited in beverages and cooked foods without any deteriorating quality effects with improved thermal and $\mathrm{pH}$ stability and fermentation resistance. Furthermore, OSHE can be manufactured as a natural sweetener because it can be extracted at high temperature and pressure using stevia leaves with only the bound water content of onion without any additional moisture from external sources. As an eco-friendly alternative of expensive enzymatic digestion or organic solvent extraction.
\end{abstract}

Keywords: onion; stevia; sensory; physiochemical; natural sweetener; hot water extraction.

Practical Application: Hot water extraction increased monosaccharide and glycoside contents of OSHE accompanied with enhanced sweetness and reduced pungent aroma of onion.

\section{Introduction}

Globally, obesity is a growing health concern. People are becoming more conscious about weight management and reduction. Hence, consumers are making informed choices about food products. Moreover, food industries are also contributing to provision of designer food products to the intended consumers (Scott et al., 2006). Broadly, sweeteners are categorized in two categories (natural and artificial sweeteners). Artificial sweeteners include aspartame, acesulfame- $\mathrm{K}$, sucralose, cyclamate, neotame, etc. Increased consumption of artificial sweeteners has led to serious health implications and safety issues (Chattopadhyay et al., 2014). Natural sweeteners are further divided into non-synthetic and extracted sweeteners (Yadav \& Guleria, 2012). Non-synthetic natural sweeteners comprise of honey, maple leaf, and molasses whereas, naturally extracted sweeteners include sucrose, polyols, and steviol glycosides (SGs). Among all natural sweeteners, SGs (stevioside \& rebaudioside-A) are popularly known as zero-caloric intense sweetening compounds of natural origin. Sweeteners usually mimic the taste of sucrose; hence, they are known as sugar substitutes (Chatsudthipong \& Muanprasat, 2009; Chattopadhyay et al., 2014). Consumers usually show preference for foods prepared from low-caloric sweeteners to manage obesity and Type-2 diabetes (Yadav \& Guleria, 2012). Artificial sweetener consumption was recently linked to several health complications that are considered global health risks, such as cardiovascular and metabolic diseases (Yracheta et al., 2015).

Replacing artificial sweeteners with natural counterparts could lead to fewer health hazards with health-promoting benefits hence; the demand for natural low-caloric sweeteners has increased in recent years to maintain improved health and well-being. Among natural low-caloric sweeteners with antioxidant properties and several health benefits, Stevia rebaudiana (Bertoni) is a well-known plant which has been used as a natural sweetener and traditional medicine (in Amambay region of Paraguay) since ancient times (Scott et al., 2006). Apart from sweetness, the bioactive compounds in S. rebaudiana also have anti-inflammatory, immunomodulatory, antimicrobial, cardiovascular, anticancer, 
and anti-diabetic properties. Stevia extracts have been widely used to sweeten foods (Ameer et al., 2017). Stevia's sweet taste is mainly attributed to several glycosides like stevioside, rebaudioside- A, -B, -C, -D, -E, and dulcoside-A. Among them, stevioside and rebaudioside A can be extracted with hot water (Biesaga \& Pyrzyńska, 2013; Kovačević et al., 2018).

Onion (Allium cepa L.) is a widely used food commodity that is famous worldwide for its unique taste, flavor, aroma, and nutritional values (Mogren et al., 2007). Onion is widely used as a potential source to manufacture natural sweeteners, and its sweetness intensity has been endorsed by many previous studies (Clark et al., 2018). Propyl allyl disulfide and allyl sulfide in onions have pungency which could vaporize and decompose during heating to form propyl mercaptan, which is known to be approximately 50 times sweeter than sucrose (Kim et al., 2010). High temperature extraction (above $100^{\circ} \mathrm{C}$ ) could enhance the hydrolysis and result in propyl mercaptan formation (Clark et al., 2018). Onion contains several bioactive compounds that have antioxidant, antibacterial, anticancer, antidiabetic, and several other health-beneficial characteristics (Benkeblia et al., 2007). However, merely onion extract was considered inappropriate to prepare a natural sweetener because of onion's unique pungent flavor. Moreover, onion hot water extract (HWE) had a strong onion flavor that negatively affects consumer preferences (Kim et al., 2009). Therefore, adding other natural sweeteners could overcome the strong onion flavor and improve the sweetness of natural onion concentrates. Onion was extracted with stevia to mask the unique flavor and improve extract sweetness. Moreover, SGs have been reported to exhibit high thermal and $\mathrm{pH}$ stability in conjunction with resistance to fermentation. SGs have remarkable $\mathrm{pH}(2-10)$ stability at elevated temperatures (up to $80^{\circ} \mathrm{C}$ ) (Kroyer, 2010). Therefore, stevia-based onion sweetener could be exploited in beverages and cooked foods without deteriorative quality effects.

HWE is considered an ecofriendly and less expensive alternative, and HWE extracts are generally safe for human consumption as compared to organic solvents extraction. HWE only involves use of hot water. Organic solvents like ethanol, acetone, methanol, $n$-hexane are toxic and may cause safety issues for intended consumers. Therefore, the use of water as a green solvent is encouraged to get high extract recoveries. Other factors that must be taken into account in this regard include solvent safety and toxicity, along with economic aspects (Ameer et al., 2017). Non-harmful solvents with lower toxicity and ease of removal are good choices. Solvents that are termed as "green" should be preferred as they cause minimum environmental impact after their usage for extraction purposes. Therefore, HWE are safe for intended consumers.

Studies on HWE of bioactive onion and stevia compounds have been reported (Kovačević et al., 2018; Petersson et al., 2010), but studies on natural sweeteners using onion-stevia hot extracts are still lacking. To the best our knowledge, no study has been conducted to prepare onion-stevia hot water extracts until now. Therefore, in this study, hot water extracts of different stevia-to-onion ratios were investigated to produce a less onion-flavored natural sweetener with an improved sweetness index. The physicochemical and sensory properties of HWE extracts were also investigated.

\section{Materials and methods}

\subsection{Materials}

Fresh onions (Allium cepa L.) were purchased from a local farm of Muan, South Korea. The top and bottom of onion bulbs were washed followed by subsequent removal and division into eight parts. Dried S. rebaudiana leaves were obtained from a local farm in Pyeongtaek, South Korea.

\subsection{Reagents, solvents and standards}

Gallic acid, (-)-catechin, Folin-Ciocalteu reagent, sucrose, and D-fructose were purchased from Sigma Aldrich (St. Louis, MO, USA). D-glucose was purchased from Ajax Finechem (Taren Point, Sydney, Australia). Sodium carbonate, sodium hydroxide, and aluminum chloride were purchased from Daejung Chemicals and Metals (Siheung, Gyeonggi-do, South Korea).

\subsection{Experimental design}

A single factor experimental design was used to optimize extraction conditions to obtain the desired physicochemical properties, sugar contents, and sensory attributes of onion-stevia extracts using two parameters: extraction temperatures $\left(105,115\right.$, and $\left.125^{\circ} \mathrm{C}\right)$ and stevia-to-onion ratio $(1: 100,2: 100$, and $3: 100, w / w)$. One parameter was varied while the other was kept constant. Extraction conditions were optimized to obtain maximum color, total soluble solids (TSS), total phenolic content (TPC), and total flavonoid content (TFC), total sweetness index (TSI), and sensory evaluation values.

\subsection{Onion-stevia hot extract (OSHE) preparation}

Onion and stevia were subjected to thermal heating at different temperatures $\left(105^{\circ} \mathrm{C}, 115^{\circ} \mathrm{C}\right.$, or $\left.125^{\circ} \mathrm{C}\right)$ and stevia-to-onion ratios $(1: 100,2: 100,3: 100, \mathrm{w} / \mathrm{w})$ for $4 \mathrm{~h}$ at $1.2 \mathrm{kgf} / \mathrm{cm}^{2}$ using a retort (STERI-ACE PRS-60-1, Kyunghan Co., Ltd, Gyeongsan, South Korea). The heated onion and stevia were juiced with a $200 \mathrm{kgf} / \mathrm{cm}^{2}$ (60 L Hydraulic Turbine, Sungchang Co., Ltd, Namyangju, South Korea) and filtered using $11 \mu \mathrm{m}$ filter paper (No. 1 filter paper, Whatman, Maidstone, UK) for analysis. Onion hot water extract (OHE) was extracted as a control without adding stevia under same extraction conditions as were those for OSHE.

\subsection{Color}

OSHE (5 mL) color was determined using a colorimeter (CR-400, Minolta, Tokyo, Japan). Calibration was performed on the white color tile prior to sample analysis $\left(L^{*}=86.90, a^{*}=0.3170\right.$, and $b^{*}=0.3240$ ). The results were expressed as color values of $L^{*}, a^{*}$, and $b^{*}$, where $L^{*}$ was used to denote degree of lightness, $a^{*}$ denoted degree of redness and greenness, and $b^{*}$ denoted degree of yellowness and blueness.

\section{$2.6 \mathrm{pH}$}

OSHE $\mathrm{pH}$ was determined using a $\mathrm{pH}$ meter (EF-7732, Istek, Seoul, South Korea). Extract $(5 \mathrm{~mL})$ was centrifuged with $45 \mathrm{~mL}$ distilled water using a centrifuge (Union 32-R plus, Hanil 
Scientific, Seoul, South Korea) at 3,000 g for $15 \mathrm{~min}$. After that, the supernatant $\mathrm{pH}$ was measured.

\subsection{Total soluble solids (TSS)}

The TSS of extracts were determined using a digital refractometer (HI 96801, Hanna Instruments Inc., Woonsocket, USA). Each onion-stevia extract $(10 \mathrm{~mL})$ was homogenized with $20 \mathrm{~mL}$ of distilled water using a homogenizer and centrifuged using a centrifuge (Union 32-R Plus, Hanil Science Industrial Co., Ltd., Daejeon, South Korea) at 3,000 g for $15 \mathrm{~min}$. The supernatants were evaluated for TSS.

\subsection{Total phenolic content}

TPC of OSHE was determined using Folin-Ciocalteu reagent (Eghdami \& Sadeghi, 2010). Diluted OSHE (250 $\mu$ L; 1/10 with distilled water) was mixed with $1.75 \mathrm{~mL}$ of Folin reagent and $0.5 \mathrm{~mL}$ of $7.5 \%$ sodium carbonate. The mixtures were kept in the dark for 30 min until reaction completion. The absorbance was measured at a wavelength of $725 \mathrm{~nm}$ using a spectrophotometer (Optizen 2120 UV, Mecasys Co., South Korea). TPC was quantified using gallic acid as the standard.

\subsection{Total flavonoid content}

TFC of OSHE was determined using the method described by Hajimahmoo et al. (2008). Diluted OSHE ( $1 \mathrm{~mL} ; 1 / 10$ with distilled water) was mixed with $0.3 \mathrm{~mL}$ of $10 \%$ aluminum chloride $\left(\mathrm{AlCl}_{3}\right)$, incubated for $6 \mathrm{~min}$, and treated with $2 \mathrm{~mL}$ of $1 \mathrm{M}$ sodium hydroxide $(\mathrm{NaOH})$. The solutions were vortexed, and the absorbance was measured at a wavelength of $510 \mathrm{~nm}$ using a spectrophotometer. TFC of sample were quantified against catechin as the standard.

\subsection{Sensory evaluation}

A sensory evaluation was conducted by 50 untrained panelists from the Department of Food Science and Technology, Chonnam National University and was approved by the Institutional Review Board (IRB) of Chonnam National University, and the granted IRB No. was 1040198-191210-HR-123-02 for informed consent and supervision of conducted sensory evaluation analysis. The sensory attributes (color, overall sweetness liking, bitterness, aftertaste, sourness, and overall acceptability) of OSHE were scored by panelists using a 5-point hedonic scale (ranging from 1 to 5) (Meilgaard et al., 2006), with 1 representing extremely disliked and 5 showing extremely liked. All participants cleansed their palates by consuming water and unsalted crackers and using expectorant cups during the intervals between samples. The obtained raw data of recorded sensory attributes by panelists was subjected to data analysis by SPSS software.

\subsection{Determination of organic sugars}

After conducting sensory evaluation, extracts obtained at each temperature prepared using the stevia-to-onion ratio with the highest overall acceptability scores were evaluated for their sugar contents.
The glucose content of OSHE was determined using method of Jermyn (1975). Diluted OSHE (250 $\mu \mathrm{L} ; 1 / 200$ with distilled water) was mixed with $1.75 \mathrm{~mL}$ of $0.2 \%$ anthrone reagent, incubated at $100^{\circ} \mathrm{C}$ for $8 \mathrm{~min}$, and chilled in cold water. The solutions were vortexed and the absorbance was measured at a wavelength of $625 \mathrm{~nm}$ using a spectrophotometer. Glucose content was determined by comparing to that of standard curve of pure glucose.

The sucrose content of OSHE was determined according to the method reported by Van Handel (1968). Diluted OSHE ( $200 \mu \mathrm{L} ; 1 / 20$ with distilled water) was mixed with $200 \mu \mathrm{L}$ of $30 \% \mathrm{KOH}$, incubated at $100^{\circ} \mathrm{C}$ for $10 \mathrm{~min}$, chilled in cold water, $1.5 \mathrm{~mL}$ of $0.2 \%$ anthrone reagent was added, and the sample was incubated at $40^{\circ} \mathrm{C}$ for $15 \mathrm{~min}$. The solutions were vortexed, and the absorbance was measured at a wavelength of $620 \mathrm{~nm}$ using a spectrophotometer. Sucrose content was determined by comparing to that of standard curve of pure sucrose.

The fructose content of OSHE was determined using method of Van Handel (1968). Diluted OSHE (500 $\mu \mathrm{L} ; 1 / 100$ with distilled water) was mixed with $1.5 \mathrm{~mL}$ of concentrated $\mathrm{HCl}$ and $500 \mu \mathrm{L}$ of resorcinol, incubated at $77^{\circ} \mathrm{C}$ for $8 \mathrm{~min}$, and chilled in cold water. The solutions were vortexed, and the absorbance was measured at a wavelength of $420 \mathrm{~nm}$ using a spectrophotometer. Fructose content was determined by comparing with that of standard curve of pure fructose.

\subsection{Total sweetness index (TSI)}

TSI is another index used in the literature to indicate sweetness of horticultural produce, where the contribution of each major component of sugar is estimated relative to sucrose, which is assigned an arbitrary value of 1 (Baldwin et al., 1998) (Equation 1).

$$
T S I=(1.00 \times[\text { sucrose }])+(0.76 \times[\text { glucose }])+(1.50 \times[\text { fructose }])
$$

\subsection{Statistical analysis}

All experiments were conducted in triplicate and presented as mean \pm standard deviation (S.D.). Statistical significance of the data was analyzed using two-way analysis of variance (ANOVA). Differences between the means were compared using Duncan's multiple-range test with SPSS version 18.0 at a significance level of $p<0.05$. Correlation matrix was obtained by statistical analysis through Origin Pro ver. 8.0 (OriginLab Corp., MA, USA). Moreover, the principal component analysis (PCA) was carried out using SPSS to elucidate numerical data trend of OSHE extracts with respect to extraction temperatures, physicochemical and sensory attributes.

\section{Result and discussions}

\subsection{Hunter color values}

The effects of different stevia-to-onion ratios and extraction temperatures on the color parameters of OHE and OSHE are shown in Table 1. $L^{*}, a^{*}$, and $b^{*}$ values decreased with corresponding increases in stevia-to-onion ratios and extraction temperatures. The Hunter color values were higher in OHE as 
compared to those observed in OSHE. The $L^{*}$ value change with corresponding changes in applied temperatures was a result of some non-enzymatic browning reactions, such as the Maillard reaction and caramelization which occured during extraction (Jousse et al., 2002). Jung et al. (2008) reported that $L^{\star}$ values of the persimmon hot water extracts decreased with increases in temperatures. In addition, decreasing $a^{*}$ values with increases in stevia-to-onion ratio and extraction temperature may be due to chlorophyll originating from stevia leaves (Simlat et al., 2019). Moreover, $a^{*}$ value rapidly decreased, and the $b^{*}$ value demonstrated a smooth decline with increased stevia-to-onion ratios. Our results suggested that OSHE at $115^{\circ} \mathrm{C}$ and a stevia-to-onion ratio of 1:100 (w/w) showed the best chlorophyll extraction yield with a limited amount of moisture (which was onion water only and excluded addition of any added water from external sources). The statistical study of variations during processing was carried out using two-way ANOVA (Table 2) for physicochemical attributes showing effects of stevia-to-onion ratio $(\mathrm{R})$, extraction temperature $(\mathrm{T})$ and interaction effect $(\mathrm{R} \times \mathrm{T})$. There was a highly significant $(p<0.01)$ interaction effect whereas, stevia-to-onion ratio (R) exerted most significant effect on Hunter color values.

\section{$3.2 \mathrm{pH}$}

Table 1 shows the $\mathrm{pH}$ of OSHE with different stevia-to-onion ratios extracted at different temperatures. The $\mathrm{pH}$ values of $\mathrm{OHE}$ and OSHE decreased with increases in temperatures and were ranged 4.50 to 5.30 and 4.46 to 5.13 , respectively. $\mathrm{pH}$ values of OSHE were not significantly $(p>0.05)$ influenced by stevia-to-onion ratios, but extraction temperatures exerted a significant effect $(p<0.05)$. The $\mathrm{pH}$ change at increased temperatures was due to the increased extraction of organic acids from onions. There was a non-significant $(p>0.05)$ interaction effect whereas, extraction temperature (T) significantly influenced $\mathrm{pH}$ of OSHE extracts. Soininen et al. (2014) determined the composition of flavonols, free amino acids, and organic acids in different Allium species using LC-MS and NMR. Likewise, the HWE extracts of onions had a higher $\mathrm{pH}$ as compared to those of extracts prepared by blending stevia leaves, which could be attributed to the effect

Table 1. Hunter color values, $\mathrm{pH}$ values and total soluble solids of onion and onion-stevia hot extracts with different stevia-to-onion ratios (w/w) and extraction temperatures

\begin{tabular}{|c|c|c|c|c|c|c|c|c|}
\hline \multicolumn{2}{|c|}{ Temperature $\left({ }^{\circ} \mathrm{C}\right)$} & Color values & \multicolumn{2}{|l|}{$\mathrm{OHE}^{*}$} & OSHE1 & \multicolumn{2}{|l|}{ OSHE2 } & OSHE3 \\
\hline 105 & & $L^{*}$ & $35.97 \pm 0.27^{j}$ & & $28.00 \pm 0.05^{\mathrm{i}}$ & $23.90 \pm 0.40^{g}$ & & $22.27 \pm 0.07^{\mathrm{f}}$ \\
\hline 115 & & & $27.39 \pm 0.08^{\mathrm{h}}$ & & $20.74 \pm 0.34^{\mathrm{e}}$ & $19.37 \pm 0.14^{\mathrm{d}}$ & & $18.86 \pm 0.09^{c}$ \\
\hline 125 & & & $19.17 \pm 0.31^{\mathrm{cd}}$ & & $17.20 \pm 0.10^{\mathrm{ab}}$ & $17.31 \pm 0.06^{\mathrm{b}}$ & & $16.90 \pm 0.27^{\mathrm{a}}$ \\
\hline 105 & & $a^{*}$ & $10.17 \pm 0.09^{\mathrm{e}}$ & & $5.10 \pm 0.11^{\mathrm{b}}$ & $5.19 \pm 0.25^{b}$ & & $3.81 \pm 0.09^{\mathrm{a}}$ \\
\hline 115 & & & $9.51 \pm 0.08^{e}$ & & $6.61 \pm 0.41^{\mathrm{c}}$ & $5.59 \pm 0.20^{\mathrm{b}}$ & & $5.14 \pm 0.11^{\mathrm{b}}$ \\
\hline 125 & & & $7.55 \pm 0.55^{\mathrm{d}}$ & & $3.56 \pm 0.21^{\mathrm{a}}$ & $3.37 \pm 0.17^{\mathrm{a}}$ & & $3.54 \pm 1.19^{\mathrm{a}}$ \\
\hline 105 & & $b^{*}$ & $15.41 \pm 0.82^{\mathrm{i}}$ & & $12.09 \pm 0.18^{\mathrm{g}}$ & $8.99 \pm 0.39^{f}$ & & $7.49 \pm 0.09^{\mathrm{e}}$ \\
\hline 115 & & & $12.78 \pm 0.10^{\mathrm{h}}$ & & $6.83 \pm 0.34^{\mathrm{d}}$ & $5.39 \pm 0.16^{c}$ & & $4.78 \pm 0.09^{\mathrm{b}}$ \\
\hline 125 & & & $4.96 \pm 0.26^{\mathrm{b}}$ & & $2.73 \pm 0.09^{\mathrm{a}}$ & $2.77 \pm 0.06^{\mathrm{a}}$ & & $2.47 \pm 0.43^{\mathrm{a}}$ \\
\hline \multirow{2}{*}{$\begin{array}{c}\text { Temperature } \\
\left({ }^{\circ} \mathrm{C}\right)\end{array}$} & \multicolumn{4}{|c|}{$\mathrm{pH}$} & \multicolumn{4}{|c|}{ Total soluble solids $\left({ }^{\circ} \mathrm{Bx}\right)$} \\
\hline & OHE & OSHE1 & OSHE2 & OSHE3 & $\mathrm{OHE}$ & OSHE1 & OSHE2 & OSHE3 \\
\hline 105 & $3.6 \pm 0.0^{\mathrm{h}}$ & $3.3 \pm 0.0^{f}$ & $3.4 \pm 0.0^{g}$ & $3.4 \pm 0.0^{g}$ & $4.9 \pm 0.2^{\mathrm{b}}$ & $5.1 \pm 0.1^{\mathrm{c}}$ & $5.7 \pm 0.2^{\mathrm{d}}$ & $6.0 \pm 0.1^{\mathrm{f}}$ \\
\hline 115 & $3.1 \pm 0.0^{\text {de }}$ & $3.1 \pm 0.0^{\mathrm{d}}$ & $3.1 \pm 0.0^{\mathrm{de}}$ & $3.1 \pm 0.0^{\mathrm{e}}$ & $4.7 \pm 0.1^{\mathrm{a}}$ & $5.7 \pm 0.1^{\mathrm{d}}$ & $5.8 \pm 0.1^{\mathrm{d}}$ & $6.0 \pm 0.1^{f}$ \\
\hline 125 & $2.8 \pm 0.0^{\mathrm{b}}$ & $2.8 \pm 0.0^{\mathrm{a}}$ & $2.8 \pm 0.0^{\mathrm{b}}$ & $2.9 \pm 0.0^{c}$ & $5.0 \pm 0.1^{\mathrm{b}}$ & $5.9 \pm 0.0^{\mathrm{e}}$ & $6.0 \pm 0.1^{\mathrm{f}}$ & $7.3 \pm 0.1^{\mathrm{g}}$ \\
\hline
\end{tabular}

${ }^{*} \mathrm{OHE}$ (onion hot water extract).

Table 2. Two-way ANOVA: F values and significance level for the effect of Stevia-to-onion ratio (R), extraction temp. (T) and interaction effect $(\mathrm{R} \times \mathrm{T})$ on physicochemical and sensory attributes.

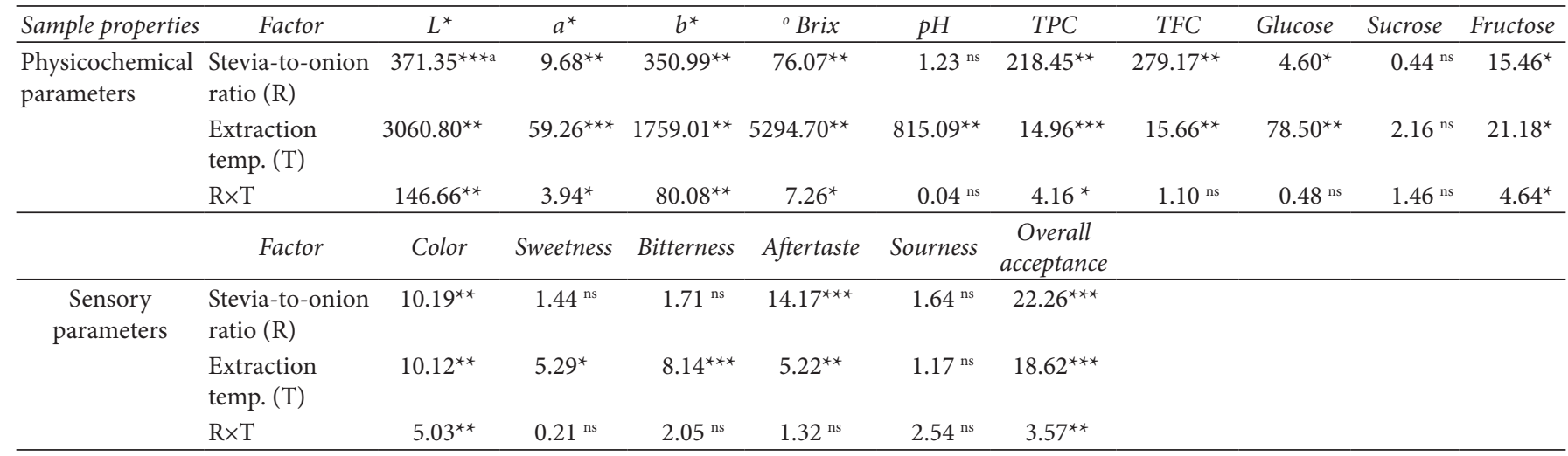

${ }^{a *} p<0.05 ;{ }^{* *} p<0.01 ;{ }^{* * *} p<0.001 ;{ }^{\text {ns }}$ non-significant. 
of gibberellic acid extracted from stevia leaves (Pazuki et al., 2019). Hence, it was evident from the results that the extraction temperature was the most influential variable which affected $\mathrm{pH}$ values of OSHE.

\subsection{Total soluble solids}

TSS is an important quality parameter used to indicate the sweetness of fresh and processed horticultural food products and determine marketing standards. The TSS of OHE and OSHE with different stevia-to-onion ratios at various extraction temperatures are shown in Table 1. TSS of OHE and OSHE increased with increased stevia-to-onion ratios, and they were in the range of 4.7 to $5.0{ }^{\circ} \mathrm{Bx}$ and 5.1 to $7.3{ }^{\circ} \mathrm{Bx}$, respectively. The TSS of onion did not significantly differ at temperatures ranging from $105-125^{\circ} \mathrm{C}$; however, OSHE showed significant increases in TSS with corresponding temperature increases. The statistical study of variations during processing was carried out using two-way ANOVA (Table 2). Effects of stevia-to-onion ratio (R), extraction temperature $(\mathrm{T})$ and interaction effect $(\mathrm{R} \times \mathrm{T})$ were considered. Results showed that interaction effect was least significant to influence TSS of OSHE extracts. The increasing TSS in OSHE may be the result of extracted free glucose, sucrose, and stevioside from stevia leaves (Ceunen \& Geuns, 2013).

\subsection{Total phenolic content}

TPCs of OHE and OSHE are shown in Figure 1a. OHE and OSHE had TPC ranging from 808.38 to $1230.70 \mu \mathrm{g} / \mathrm{mL}$ and 1203.88 to $1903.12 \mu \mathrm{g} / \mathrm{mL}$, respectively. TPC showed significant $(p<0.05)$ rises with increased extraction temperatures. The statistical study of variations during processing was carried out using two-way ANOVA (Table 2) for physicochemical attributes showing effects of stevia-to-onion ratio $(\mathrm{R})$, extraction temperature $(\mathrm{T})$ and interaction effect $(\mathrm{R} \times \mathrm{T})$. There was significant $(p<0.01)$ interaction effect whereas, extraction temperature $(\mathrm{T})$ exerted most significant effect on TPC of OSHE extracts. These results agreed with observations by Sharma et al. (2015) and (Kovačević et al. (2018), who reported that TPC increased with increases in extraction temperatures when onion was heated at $80{ }^{\circ} \mathrm{C}, 100^{\circ} \mathrm{C}, 120^{\circ} \mathrm{C}$, and $150^{\circ} \mathrm{C}$ for $30 \mathrm{~min}$ using an oven. Moreover, increased extraction temperatures and amount of stevia leaves showed linear increases in OSHE TPC. The increased TPC might be the result adding phenolic compounds from onion liberated by heating and cleavage of esterification and glycosylation bonds or phenolic compound formation due to the Maillard reaction (Maillard et al., 1996). Furthermore, increased temperatures led to enhanced solvent extraction by accelerating polyphenolic compound diffusion and solubility (Al-Farsi \& Lee, 2008) followed by bound polyphenol mass transfer and release in a sample due to plant cell constituent breakdown which led to increased cell membrane permeability (Wang et al., 2008).

Stevia-to-onion ratios caused ratio-dependent significant increases in OSHE TPC. Similarly, Kim et al. (2011) reported that stevia leaf solubilized phenolic compounds of pyrogallol, 4-methoxybenzoic acid, $p$-coumaric acid, 4-methylcatechol, sinapic acid, and cinnamic acid in hot water extracted at $100^{\circ} \mathrm{C}$ for $3 \mathrm{~h}$. The TPC of water extract increased with corresponding increases of temperatures due to decreased water polarity (low dielectric constants) at higher temperatures (Wahyudiono et al., 2008). Therefore, onion-stevia extracts could become a functional natural sweetener in food product formulation due to their high total phenolic and bioactive compound content

\subsection{Total Flavonoid Content (TFC)}

The TFC of OHE and OSHE are shown in Figure $1 \mathrm{~b}$. TFC of OHE and OSHE ranged from 161.82 to $283.84 \mu \mathrm{g} / \mathrm{mL}$ and 815.84 to $1760.23 \mu \mathrm{g} / \mathrm{mL}$, respectively. Onion contains a wide range of flavonoid compounds including quercetin and kaempferol; however, these are thermally instable in boiling water (Ioku et al., 2001). Moreover, Makris \& Rossiter (2001) reported that quercetin-3,4'-O-diglucoside leaching was favored during boiling.

Here, onion and stevia leaves were extracted for $4 \mathrm{~h}$ at temperatures above $105^{\circ} \mathrm{C}$, and TFC decreased significantly with corresponding rises in extraction temperatures. The statistical study of variations during processing was carried out using two-way ANOVA (Table 2). Effects of stevia-to-onion ratio (R), extraction temperature $(\mathrm{T})$ and interaction effect $(\mathrm{R} \times \mathrm{T})$ were considered. There was a non-significant $(p>0.05)$ interaction effect whereas, extraction temperature (T) significantly $(p<0.01)$ influenced TFC of OSHE extracts. This could be due to the thermal degradation of flavonoids at elevated temperatures, and

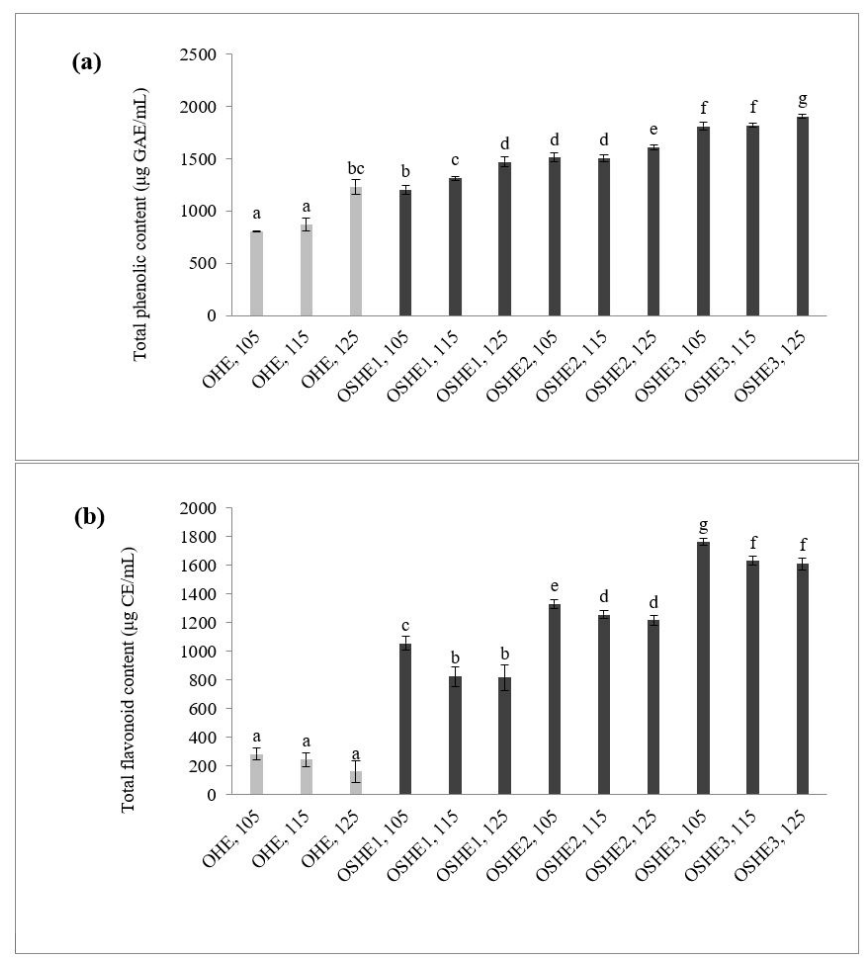

Figure 1. Total phenolic ( $\mu \mathrm{g} \mathrm{GAE} / \mathrm{mL}$ ) (a) and flavonoid ( $\mu \mathrm{g} \mathrm{CE} / \mathrm{mL}$ ) contents (b) of onion and onion-stevia hot extracts with different stevia-to-onion ratios $(\mathrm{w} / \mathrm{w})$ and extraction temperatures. 105, 115, and 125 - extracted at $105^{\circ} \mathrm{C}, 115^{\circ} \mathrm{C}$, and $125^{\circ} \mathrm{C}$ for $4 \mathrm{~h}$, respectively. OHE: onion hot extract; OSHE1: onion-stevia leaves hot extract in stevia-to-onion ratio 1:100 (w/w); OSHE2: onion-stevia leaves hot extract in stevia-to-onion ratio 2:100 (w/w); OSHE3: onion-stevia leaves hot extract in stevia-to-onion ratio 3:100 (w/w) $(p<0.05)$. 
it was consistent with findings of Prommuak et al. (2008) who also reported decreases in TFC of Thai silk water extract with corresponding increases in extraction time and temperature. In addition, our results agreed with those of Ioku et al. (2001), who found that TFC increased after heating onion at a certain temperature and time, while heating for $3 \mathrm{~h}$ at $150^{\circ} \mathrm{C}$ decreased the TFC. Furthermore, Sharma et al. (2015) reported that flavonoid content decreased when onion was heated at $150{ }^{\circ} \mathrm{C}$ for $30 \mathrm{~min}$. These decreases were higher as compared to those in onion heated at $90^{\circ} \mathrm{C}$ and $120^{\circ} \mathrm{C}$ under same conditions. However, the Kovačević et al. (2018) found no significant differences in TFC of stevia leaf water extract at elevated temperatures and pressures.

The TFC of OSHE significantly increased as the stevia-to-onion ratio increased. This was consistent with findings of Kim et al. (2011), who revealed a TFC of $15.64 \mathrm{mg} / \mathrm{g}$ from stevia leaves using hot water extract at $100{ }^{\circ} \mathrm{C}$ for $3 \mathrm{~h}$. Unlike TPC, this suggests that increases in temperature negatively affected the TFC of OHE and OSHE.

\subsection{Sensory evaluation}

Table 3 shows the sensory attributes of OHE and OSHE with increases of stevia-to-onion ratio and extraction temperature. Increases in stevia-to-onion ratio and extraction temperature led to decreased color scores of OHE and OSHE. While at same temperature, stevia-onion ration caused slight decreases in color preference of OSHE extracts (Table 3) as compared to OHE. The sweetness of OSHE was higher than that of OHE. However, there was no significant difference $(p>0.05)$ in sweetness of OSHE due to varying stevia-to-onion ratios. In contrast, scores in bitterness, aftertaste, and sourness of OHE and OSHE were not significantly different due to increased stevia-to-onion ratio and extraction temperature.
The OSHE obtained at $115^{\circ} \mathrm{C}$ temperature and stevia-to-onion ratio of 1:100 $(\mathrm{w} / \mathrm{w})$ received the highest overall acceptability score. The statistical study of variations during processing was carried out using two-way ANOVA (Table 2). Effects of stevia-to-onion ratio $(\mathrm{R})$, extraction temperature $(\mathrm{T})$ and interaction effect $(\mathrm{R} \times \mathrm{T})$ were considered. There was a highly significant $(p<0.01)$ interaction effect for fructose whereas, interaction effect was non-significant $(p>0.05)$ for both glucose and sucrose. Stevia-to-onion ratio $(\mathrm{R})$ and extraction temperature $(\mathrm{T})$ exerted most significant effect on glucose and fructose, whereas sucrose exhibited non-significant $(p>0.05)$ effect as evident from two-way ANOVA results. The results of the correlation analysis in terms of correlation matrix of sensory properties of onion and onion-stevia hot water extracts; OSHE1 (1:100 stevia-to-onion ratio), OSHE2 (2:100 stevia-to-onion ratio), OSHE3 (3:100 stevia-to-onion ratio) are given in Figure 2. Highest correlation of $0.96,0.81,0.76,0.89,0.92,0.93,0.79,0.96$, 0.87 were found for color, sweetness, bitterness, and aftertaste against respective parameters shown in Figure 2. Among overall acceptance parameters of OSHE1, color, sweetness, bitterness, aftertaste, and sourness showed fairly higher correlation coefficients with respect to overall acceptance. Whereas, overall acceptance showed lower magnitude of correlation coefficients in case of OSHE3.

Principle component analysis (PCA) biplot for sensory attributes of OHE and OSHE is shown in supplementary Figure 1. The PCA shows the differences and similarities of OHE and OSHE with respect to their sensory attributes. Analytical variables explained $85.6 \%$ of the variability along first two components of PCA scope plot: PC1 (58.1\%) and PC2 (27.5\%). All sensory attributes like color, bitterness, aftertaste, and overall acceptability decreased along PC1, whereas sweetness attribute and sweetness index increased along PC2. This suggested that OSHE explained

Table 3. Sensory attributes of onion and onion-stevia hot extracts with different stevia-to-onion ratios (w/w) and extraction temperatures.

\begin{tabular}{|c|c|c|c|c|c|}
\hline Temperature $\left({ }^{\circ} \mathrm{C}\right)$ & Parameters & OHE & OSHE1 & OSHE2 & OSHE3 \\
\hline 105 & Color & $5.7 \pm 1.9^{\mathrm{d}}$ & $5.3 \pm 1.5^{\mathrm{cd}}$ & $4.5 \pm 0.8^{\mathrm{abcd}}$ & $4.3 \pm 1.3^{\mathrm{abcd}}$ \\
\hline 115 & & $5.4 \pm 1.3^{\mathrm{cd}}$ & $5.0 \pm 1.3^{\mathrm{bcd}}$ & $4.0 \pm 1.4^{\mathrm{abc}}$ & $3.4 \pm 1.4^{\mathrm{a}}$ \\
\hline 125 & & $3.6 \pm 1.3^{\mathrm{ab}}$ & $3.7 \pm 1.3^{\mathrm{ab}}$ & $3.8 \pm 1.6^{\mathrm{ab}}$ & $3.2 \pm 1.5^{\mathrm{a}}$ \\
\hline 105 & Overall sweetness & $2.8 \pm 0.8^{\mathrm{a}}$ & $5.2 \pm 1.5^{c}$ & $5.0 \pm 1.1^{c}$ & $4.7 \pm 1.3^{c}$ \\
\hline 115 & liking & $3.2 \pm 1.8^{\mathrm{ab}}$ & $5.4 \pm 1.3^{\mathrm{c}}$ & $5.5 \pm 1.6^{c}$ & $5.1 \pm 1.6^{c}$ \\
\hline 125 & & $2.9 \pm 1.7^{\mathrm{a}}$ & $4.4 \pm 1.3^{\mathrm{bc}}$ & $4.8 \pm 1.5^{\mathrm{c}}$ & $4.2 \pm 2^{\mathrm{abc}}$ \\
\hline 105 & Bitterness & $4.8 \pm 2.1^{\mathrm{a}}$ & $4.4 \pm 1.3^{\mathrm{a}}$ & $4.1 \pm 1.2^{\mathrm{a}}$ & $3.7 \pm 2.0^{\mathrm{a}}$ \\
\hline 115 & & $4.4 \pm 1.8^{\mathrm{a}}$ & $4.9 \pm 1.9^{\mathrm{a}}$ & $4.9 \pm 1.8^{\mathrm{a}}$ & $4.3 \pm 1.8^{\mathrm{a}}$ \\
\hline 125 & & $3.9 \pm 2.2^{\mathrm{a}}$ & $4.0 \pm 1.9^{\mathrm{a}}$ & $3.9 \pm 1.5^{\mathrm{a}}$ & $4.3 \pm 2.2^{\mathrm{a}}$ \\
\hline 105 & Aftertaste & $4.3 \pm 1.3^{\mathrm{abc}}$ & $4.7 \pm 1.3^{\mathrm{bc}}$ & $4.4 \pm 1.2^{\mathrm{abc}}$ & $3.8 \pm 1.3^{\mathrm{abc}}$ \\
\hline 115 & & $4.4 \pm 1.6^{\mathrm{abc}}$ & $5.1 \pm 1.3^{c}$ & $4.0 \pm 1.9^{\mathrm{abc}}$ & $3.4 \pm 1.6^{\mathrm{ab}}$ \\
\hline 125 & & $3.1 \pm 1.3^{\mathrm{a}}$ & $4.0 \pm 1.6^{\mathrm{abc}}$ & $3.7 \pm 1.6^{\mathrm{abc}}$ & $3.3 \pm 1.5^{\mathrm{ab}}$ \\
\hline 105 & Sourness & $3.7 \pm 1.9^{\mathrm{ab}}$ & $4.2 \pm 1.5^{\mathrm{ab}}$ & $4.8 \pm 1.4^{\mathrm{b}}$ & $4.1 \pm 1.7^{\mathrm{ab}}$ \\
\hline 115 & & $3.5 \pm 1.8^{\mathrm{ab}}$ & $4.6 \pm 1.8^{\mathrm{ab}}$ & $4.3 \pm 1.9^{\mathrm{ab}}$ & $3.9 \pm 1.6^{\mathrm{ab}}$ \\
\hline 125 & & $2.9 \pm 1.2^{\mathrm{a}}$ & $4.2 \pm 1.6^{\mathrm{ab}}$ & $3.9 \pm 1.5^{\mathrm{ab}}$ & $4.2 \pm 1.8^{\mathrm{ab}}$ \\
\hline 105 & Overall acceptability & $4.3 \pm 1.5^{\mathrm{abcd}}$ & $5.1 \pm 1.4^{\mathrm{cd}}$ & $4.7 \pm 1.1^{\mathrm{bcd}}$ & $4.1 \pm 1.2^{\mathrm{abc}}$ \\
\hline 115 & & $4.4 \pm 1.7^{\mathrm{abcd}}$ & $5.8 \pm 1.5^{\mathrm{d}}$ & $4.4 \pm 2.0^{\mathrm{abcd}}$ & $3.8 \pm 1.6^{\mathrm{abc}}$ \\
\hline 125 & & $3.0 \pm 0.9^{\mathrm{a}}$ & $3.9 \pm 1.4^{\mathrm{abc}}$ & $3.9 \pm 1.8^{\mathrm{abc}}$ & $3.3 \pm 1.9^{\mathrm{ab}}$ \\
\hline
\end{tabular}

OHE: onion hot water extract; OSHE1: onion-stevia leaves hot extract in stevia-to-onion ratio 1:100 (w/w); OSHE2: onion-stevia leaves hot extract in stevia-to-onion ratio 2:100 (w/w); OSHE3: onion-stevia leaves hot extract in stevia-to-onion ratio 3:100 (w/w) $(p<0.05)$. 
majority of variability and exhibited high overall acceptability at independent variables of $115^{\circ} \mathrm{C}$ extraction temperature and stevia-to-onion ratio of 1:100 (w/w). These findings agreed with the results of Choi \& Surh (2014), who reported that onion juice heated at $120^{\circ} \mathrm{C}$ for $5.5 \mathrm{~h}$ led to stronger sweetness, concentrated taste, and bitter aftertaste as compared to onion juice heated at $105^{\circ} \mathrm{C}$ for $5 \mathrm{~h}$. Based on PCA results, the optimum extraction conditions for preparing OSHE sweetener were extraction temperature of $115^{\circ} \mathrm{C}$ and stevia-to-onion ratio 1:100 (w/w).

\subsection{Sugar contents}

According to results of sensory evaluation, extracts prepared using stevia-to-onion ratio of 1:100 (w/w) exhibited higher sensory scores as compared to those prepared using other ratios. Thus, the glucose, sucrose, and fructose contents of OSHE prepared with stevia-to-onion ratio of 1:100 (w/w) were measured at various extraction temperatures.

The effects of different extraction temperatures on the glucose, sucrose, and fructose contents of OHE and OSHE at 1:100 (w/w) stevia-to-onion ratio are shown in Figure 3. On basis of dry weights, onion bulbs are reportedly comprised of carbohydrate compounds including glucose, fructose, sucrose, and fructooligosaccharides with polymerization degrees of 3-12 (Suzuki \& Cutcliffe, 1989). Another report showed that onion predominantly contains glucose followed by fructose and sucrose (Sharma et al., 2015). Our results indicated that both OHEs and OSHEs exhibited the highest glucose contents followed by sucrose and fructose. This could be attributed to the fact that fructose degrades faster than other sugars at elevated temperatures. Reyes et al. (1982) reported that thermal treatment at elevated temperatures led to faster initial reduction of fructose content compared to that of glucose, but glucose loss later overtook fructose loss. OHE and OSHE demonstrated high fructose contents at $115^{\circ} \mathrm{C}$ compared to that of extracts obtained at $125^{\circ} \mathrm{C}$. However, OSHEs showed increased fructose content in their compositions and this might be attributed to organic sugar contribution owing to addition of stevia leaves to onion.

On the other hand, glucose content decreased with increased extraction temperatures. Sucrose and fructose contents were the highest at $115^{\circ} \mathrm{C}$ temperature and the lowest at $125^{\circ} \mathrm{C}$ regardless of extract type. These decreases in sugar contents might be due to the formation of Maillard reaction products formed by the reaction between sugars, amino acids, and proteins (Martins et al., 2000). The nature of the reducing sugars and amino groups also affects Maillard reaction speed. This might be the reason of decreases in glucose content at initial stages rather than fructose. This would mean that the Maillard reaction occurs faster with glucose than fructose. Like fructose, sucrose content as a non-reducing sugar also decreased at thermal treatments above $115{ }^{\circ} \mathrm{C}$. This could be attributed to the breakdown of sucrose into glucose and fructose at elevated temperatures. Sharma et al. (2015) suggested maintenance of onion powder sweetness during onion processing, and they concluded that one should completely prohibit heating above $120^{\circ} \mathrm{C}$ temperatures. Therefore, heating onions at $125^{\circ} \mathrm{C}$ may have an adverse effect on OHE and OSHE sweetness.
The total sweetness index of OHEs and OSHEs is shown in Figure $3 \mathrm{~d}$. The total sweetness index of OSHE at $115^{\circ} \mathrm{C}$ extraction temperature and stevia-to-onion ratio of 1:100 $(\mathrm{w} / \mathrm{w})$ was the highest due to relatively major contributions from sucrose

\begin{tabular}{|c|c|c|c|c|c|c|}
\hline$\ldots$ & & & OSHE1 & & & \\
\hline$\cdots$ & Color & Sweetness & Bitterness & Aftertaste & Sourness & Overall acceptance \\
\hline Color & & -0.071 & 0.024 & 0.304 & 0.31 & 0.619 \\
\hline Sweetness & 0.071 & & -0.893 & 0.958333333 & 0.813 & 0.762 \\
\hline Bitterness & 0.024 & 0.893 & & -0.917 & 0.932 & 0.798 \\
\hline Aftertaste & 0.304 & 0.958333333 & 0.917 & & -0.759 & 0.887 \\
\hline Sourness & 0.31 & 0.813 & 0.932 & 0.759 & & 0.61 \\
\hline Overall acceptance & 0.619 & 0.762 & 0.798 & 0.887 & 0.61 & \\
\hline & & & OSHE2 & & & \\
\hline$\pi$ & Color & Sweetness & Bitterness & Aftertaste & Sourness & Overall acceptance \\
\hline Color & $\therefore$ & 0.622 & 0.03 & 0.048 & 0.054 & 0.131 \\
\hline Sweetness & 0.622 & & 0.164 & 0.688 & 0.705 & 0.705 \\
\hline Bitterness & 0.03 & 0.164 & & 0.256 & 0.512 & 0.536 \\
\hline Aftertaste & 0.048 & 0.688 & 0.256 & & 0.935 & 0.905 \\
\hline Sourness & 0.054 & 0.705 & 0.512 & 0.935 & & 0.97 \\
\hline Overall acceptance & 0.131 & 0.705 & 0.536 & 0.905 & 0.97 & \\
\hline & & & OSHE3 & & & \\
\hline & Color & Sweetness & Bitterness & Aftertaste & Sourness & Overall acceptance \\
\hline Color & & 0.49 & 1.42 & 0.125 & 0.37 & 0.387 \\
\hline Sweetness & 0.49 & & 0.381 & 0.607 & 0.068 & 0.53 \\
\hline Bitterness & 1.42 & 0.381 & & 0.03 & 0.277 & 0.57 \\
\hline Aftertaste & 0.125 & 0.607 & 0.03 & & 0.693 & 0.774 \\
\hline Sourness & 0.37 & 0.068 & 0.277 & 0.693 & & 0.068 \\
\hline Overall acceptance & 0.387 & 0.53 & 0.57 & 0.774 & 0.068 & \\
\hline
\end{tabular}

Figure 2. Correlation matrix of sensory properties of onion and onion-stevia hot extracts, OSHE1: onion-stevia leaves hot extract in stevia-to-onion ratio 1:100 (w/w); OSHE2: onion-stevia leaves hot extract in stevia-to-onion ratio 2:100 (w/w); OSHE3: onion-stevia leaves hot extract in stevia-to-onion ratio 3:100 (w/w) $(p<0.05)$.
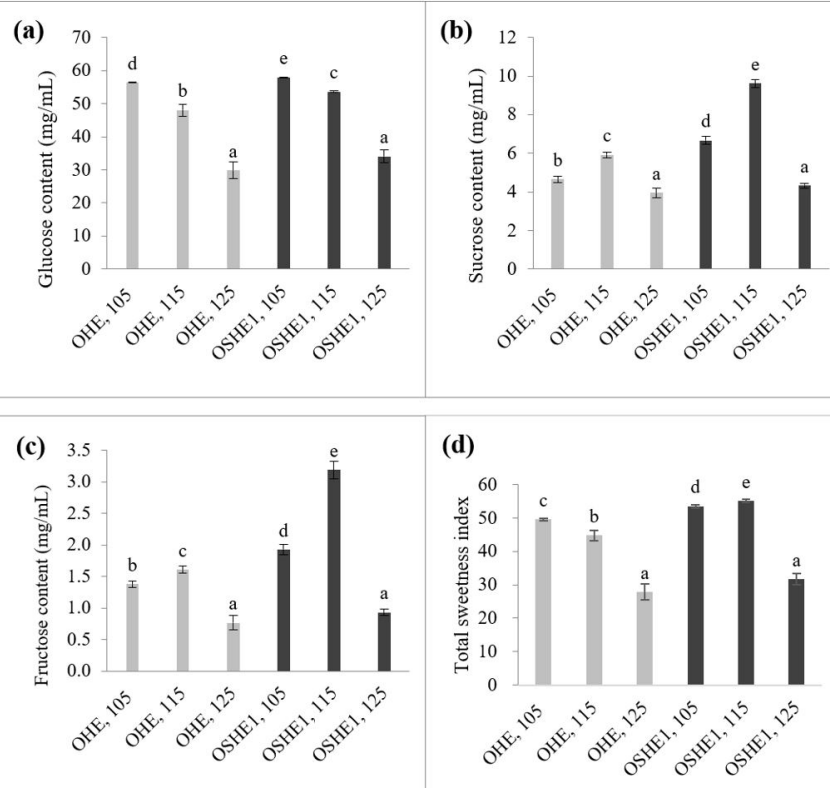

Figure 3. The glucose (a), sucrose (b), and fructose (c) contents and total sweetness index (d) of onion and onion-stevia hot extracts extracted at $105^{\circ} \mathrm{C}, 115^{\circ} \mathrm{C}$, and $125^{\circ} \mathrm{C}$ for $4 \mathrm{~h}$. OHE: onion hot extract; OSHE1: onion-stevia leaves hot extract in stevia-to-onion ratio 1:100 $(\mathrm{w} / \mathrm{w})(p<0.05)$. 
and fructose. This implied that OSHE at $115^{\circ} \mathrm{C}$ exhibited the highest sweetness compared to that of extracts obtained at other temperatures. Therefore, the optimum extraction temperature of extracts with maximum sweetness index was determined to be $115^{\circ} \mathrm{C}$. The statistical study of variations during processing was carried out using two-way ANOVA (Table 2). Effects of stevia-to-onion ratio $(\mathrm{R})$, extraction temperature $(\mathrm{T})$ and interaction effect $(\mathrm{R} \times \mathrm{T})$ were considered. Decreasing pungency or astringency of extracts by increasing sweetness or adding taste improvers have been reported in previously published literature, such as taste improvement using a combination of $\alpha$-glucosyl rebaudioside and stevia extract (Purkayastha \& Markosyan, 2015), using kelp extract as a taste improver to decrease bitter aftertaste of stevia extract (Ikeda et al., 2011), pullulan, alginate, Karaya gum, xanthan gum as a taste improver for stevia extract (Nachbagauer et al., 2016), using L-histidine hydrochloride as a taste improver for stevioside, organic acid salt as a taste improver for stevioside (Prakash et al., 2008), glycyrrhizic acid or its salts, which are used in sweeteners, health food materials and Chinese herbs, have bitterness, unpleasant taste, astringency, and a method using rebaudioside- $\mathrm{A}$ has been reported to reduce bitterness and astringency (Bridges et al., 2016). In addition, processed soybean products have been reported to exhibit bitterness and astringency while reduction of astringent taste has been reported by addition of cyclodextrin (Szejtli \& Szente, 2005).

\section{Conclusions}

In conclusion, the results revealed that the extraction temperature and stevia-to-onion ratio had highly significant $(p<0.05)$ influences on the physicochemical properties and sensory attributes of OHEs (control) and OSHEs. The physicochemical properties of OSHEs were significantly different when compared to those of OHEs. The main difference in terms of sugar content was that OSHE was sweeter than OHE. Especially, in sensory evaluation, the PCA results indicated that OSHEs obtained at $115^{\circ} \mathrm{C}$ and stevia-to-onion ratios of $1: 100(\mathrm{w} / \mathrm{w})$ were correlated with higher overall acceptability. Therefore, the OSHE obtained at $115^{\circ} \mathrm{C}$ temperature and stevia-to-onion ratio of 1:100 (w/w) could be produced as a natural sweetener after concentration or drying.

In contrast to the commercial onion sweetener extracted using enzymes or solvents, OSHE can be manufactured as a natural sweetener because it can be extracted at high temperature and pressure using stevia leaves with only the bound water content of onion without any additional moisture from external sources. Therefore, expensive and complex processing procedures involving enzymatic digestion or solvent extraction can be replaced by simple and natural process of hot water extraction. Additionally, this natural process is more functional and economical because no additional solvent is required. In addition, this process is expected to increase monosaccharide and glycoside contents of OSHE to enhance the sweetness and reduce spicy and pungent aroma of onion. The process may substantially replace sugars and oligosaccharides using onion and stevia leaves. Furthermore, this natural process can extract functional ingredients from onion and stevia leaves like solvent extraction. More studies are needed to better understand OSHE concentration or drying for commercial manufacturing to meet consumer needs.

\section{Conflict of interest}

Authors have no conflict of interest to declare.

\section{Acknowledgements}

This work was supported by "Local Demand Tailored Research \& Development (Project No. B0080716000106)" Jeonnam Technopark, Republic of Korea. Also, we would like to thank Editage (www.editage.co.kr) for English language editing.

\section{References}

Ameer, K., Bae, S. W., Jo, Y., Lee, H. G., Ameer, A., \& Kwon, J. H. (2017). Optimization of microwave-assisted extraction of total extract, stevioside and rebaudioside: a from Stevia rebaudiana (Bertoni) leaves, using response surface methodology (RSM) and artificial neural network (ANN) modelling. Food Chemistry, 229, 198-207. http://dx.doi.org/10.1016/j.foodchem.2017.01.121. PMid:28372164.

Al-Farsi, M. A., \& Lee, C. Y. (2008). Optimization of phenolics and dietary fibre extraction from date seeds. Food Chemistry, 108(3), 977-985. http://dx.doi.org/10.1016/j.foodchem.2007.12.009. PMid:26065761.

Baldwin, E. A., Scott, J. W., Einstein, M. A., Malundo, T. M. M., Carr, B. T., Shewfelt, R. L., \& Tandon, K. S. (1998). Relationship between sensory and instrumental analysis for tomato flavor. Journal of the American Society for Horticultural Science, 123(5), 906-915. http:// dx.doi.org/10.21273/JASHS.123.5.906.

Benkeblia, N., Shiomi, N., \& Osaki, M. (2007). Kinetics and hydrolysis parameters of total fructooligosaccharides of onion bulbs: effects of temperature regimes and cultivars. Journal of Food Biochemistry, 31(1), 14-27. http://dx.doi.org/10.1111/j.1745-4514.2007.00095.x.

Biesaga, M., \& Pyrzyńska, K. (2013). Stability of bioactive polyphenols from honey during different extraction methods. Food Chemistry, 136(1), 46-54. http://dx.doi.org/10.1016/j.foodchem.2012.07.095. PMid:23017391.

Bridges, J. R., Carlson, A., \& Patton, P. A. (2016). U.S. Patent No. 9,402,411. Washington, DC: U.S. Patent and Trademark Office.

Ceunen, S., \& Geuns, J. M. C. (2013). Glucose, sucrose, and steviol glycoside accumulation in Stevia rebaudiana grown under different photoperiods. Biologia Plantarum, 57(2), 390-394. http://dx.doi. org/10.1007/s10535-012-0289-6.

Chattopadhyay, S., Raychaudhuri, U., \& Chakraborty, R. (2014). Artificial sweeteners-a review. Journal of Food Science and Technology, 51(4), 611-621.http://dx.doi.org/10.1007/s13197-011-0571-1. PMid:24741154.

Chatsudthipong, V., \& Muanprasat, C. (2009). Stevioside and related compounds: therapeutic benefits beyond sweetness. Pharmacology \& Therapeutics, 121(1), 41-54. http://dx.doi.org/10.1016/j. pharmthera.2008.09.007. PMid:19000919.

Choi, B., \& Surh, J. (2014). Effects of heat treatment on the quality of the onion juices prepared with sulfur-applied onions. Korean Journal of Food Science Technology, 46(2), 189-197. http://dx.doi. org/10.9721/KJFST.2014.46.2.189.

Clark, C. J., Shaw, M. L., Wright, K. M., \& McCallum, J. A. (2018). Quantification of free sugars, fructan, pungency and sweetness indices in onion populations by FT-MIR spectroscopy. Journal of the Science of Food and Agriculture, 98(14), 5525-5533. http://dx.doi. org/10.1002/jsfa.9099. PMid:29687887.

Eghdami, A., \& Sadeghi, F. (2010). Determination of total phenolic and flavonoids contents in methanolic and aqueous extract of Achillea millefolium. Organic Chemistry Journal, 2, 81-84. 
Hajimahmoo, M., Sadeghi, N., Jannat, B., Oveisi, M. R., Madani, S., Kiayi, M., Akrami, M. R., \& Ranjbar, A. M. (2008). Antioxidant activity, reducing power and total phenolic content of Iranian olive cultivar. The Journal of Biological Sciences, 8(4), 779-783. http:// dx.doi.org/10.3923/jbs.2008.779.783.

Ikeda, K., Tashiro, S., Hamada, S., \& Sato, K. (2011). U.S. Patent No. 7,867,520. Washington, DC: U.S. Patent and Trademark Office.

Ioku, K., Aoyama, Y., Tokuno, A., Terao, J., Nakatani, N., \& Takei, Y. (2001). Various cooking methods and the flavonoid content in onion. Journal of Nutritional Science and Vitaminology, 47(1), 78-83. http:// dx.doi.org/10.3177/jnsv.47.78. PMid:11349895.

Jermyn, M. A. (1975). Increasing the sensitivity of the anthrone method for carbohydrate. Analytical Biochemistry, 68(1), 332-335. http:// dx.doi.org/10.1016/0003-2697(75)90713-7. PMid:1190448.

Jousse, F., Jongen, T., Agterof, W., Russell, S., \& Braat, P. (2002). Simplified kinetic scheme of flavor formation by the Maillard reaction. Journal of Food Science, 67(7), 2534-2542. http://dx.doi. org/10.1111/j.1365-2621.2002.tb08772.x.

Jung, J. S., Park, J. S., \& Kim, T. K. (2008). Coloration of cotton fabrics with tannins of persimmon extracts by heating process. Textile Coloration and Finishing, 20(3), 25-30. http://dx.doi.org/10.5764/ TCF.2008.20.3.025.

Kroyer, G. (2010). Stevioside and Stevia-sweetener in food: application, stability and interaction with food ingredients. Journal of Consumer Protection and Food Safety, 5(2), 225-229. http://dx.doi.org/10.1007/ s00003-010-0557-3.

Kim, I. S., Yang, M., Lee, O. H., \& Kang, S. N. (2011). The antioxidant activity and the bioactive compound content of Stevia rebaudiana water extracts. Lebensmittel-Wissenschaft + Technologie, 44(5), 1328-1332. http://dx.doi.org/10.1016/j.lwt.2010.12.003.

Kim, J. Y., Seo, Y. J., Noh, S. K., \& Cha, Y. J. (2010). A concentrated onion extract lowers serum lipid levels in rats fed a high-fat diet. Korean Journal of Food Preservation, 17(3), 398-404.

Kim, S. R., Kim, C. S., \& Oh, H. J. (2009). Study on the perceptions and purchasing realities of consumers for onion hot-water extracts. Korean Journal of Food and Cookery Science, 25(4), 395-405.

Kovačević, D. B., Barba, F. J., Granato, D., Galanakis, C. M., Herceg, Z., Dragović-Uzelac, V., \& Putnik, P. (2018). Pressurized hot water extraction (PHWE) for the green recovery of bioactive compounds and steviol glycosides from Stevia rebaudiana Bertoni leaves. Food Chemistry, 254, 150-157. http://dx.doi.org/10.1016/j. foodchem.2018.01.192. PMid:29548436.

Maillard, M. N., Soum, M. H., Boivin, P., \& Berset, C. (1996). Antioxidant activity of barley and malt: relationship with phenolic content. Lebensmittel-Wissenschaft + Technologie, 29(3), 238-244. http:// dx.doi.org/10.1006/fstl.1996.0035.

Makris, D. P., \& Rossiter, J. T. (2001). Domestic processing of onion bulbs (Allium cepa) and asparagus spears (Asparagus officinalis): effect on flavonol content and antioxidant status. Journal of Agricultural and Food Chemistry, 49(7), 3216-3222. http://dx.doi.org/10.1021/ jf001497z. PMid:11453754.

Martins, S. I., Jongen, W. M., \& Van Boekel, M. A. (2000). A review of Maillard reaction in food and implications to kinetic modelling. Trends in Food Science \& Technology, 11(9-10), 364-373. http:// dx.doi.org/10.1016/S0924-2244(01)00022-X.

Meilgaard, M. C., Carr, B. T., \& Civille, G. V. (2006). Sensory evaluation techniques. Boca Raton: CRC Press. http://dx.doi.org/10.1201/b16452.
Mogren, L. M., Olsson, M. E., \& Gertsson, U. E. (2007). Effects of cultivar, lifting time and nitrogen fertiliser level on quercetin content in onion (Allium cepa L.) at lifting. Journal of the Science of Food and Agriculture, 87(3), 470-476. http://dx.doi.org/10.1002/jsfa.2735.

Nachbagauer, J., Gansch, H., Goehler, L., Habring, S., \& Nicole, P. A. B. I. (2016). U.S. Patent Application No. 14/923,304. Washington, DC: U.S. Patent and Trademark Office.

Prakash, I., Dubois, G. E., King, G. A., Upreti, M., Klucik, J., \& San Miguel, R. I. (2008). U.S. Patent Application No. 12/120,874. Washington, DC: U.S. Patent and Trademark Office.

Pazuki, A., Aflaki, F., Yücesan, B., \& Gürel, S. (2019). Effects of cytokinins, gibberellic acid 3 , and gibberellic acid $4 / 7$ on in vitro growth, morphological traits, and content of steviol glycosides in Stevia rebaudiana. Plant Physiology and Biochemistry, 137, 154-161. http://dx.doi.org/10.1016/j.plaphy.2019.02.009. PMid:30784987.

Petersson, E. V., Liu, J., Sjöberg, P. J., Danielsson, R., \& Turner, C. (2010). Pressurized hot water extraction of anthocyanins from red onion: A study on extraction and degradation rates. Analytica Chimica Acta, 663(1), 27-32. http://dx.doi.org/10.1016/j.aca.2010.01.023. PMid:20172092.

Prommuak, C., De-Eknamkul, W., \& Shotipruk, A. (2008). Extraction of flavonoids and carotenoids from Thai silk waste and antioxidant activity of extracts. Separation and Purification Technology, 62(2), 444-448. http://dx.doi.org/10.1016/j.seppur.2008.02.020.

Purkayastha, S., \& Markosyan, A. (2015). U.S. Patent No. 9,107,436. Washington, DC: U.S. Patent and Trademark Office.

Reyes, F. G., Poocharoen, B., \& Wrolstad, R. E. (1982). Maillard browning reaction of sugar-glycine model systems: changes in sugar concentration, color and appearance. Journal of Food Science, 47(4), 1376-1377. http://dx.doi.org/10.1111/j.1365-2621.1982.tb07690.x.

Scott, S. K., Rabito, F. A., Price, P. D., Butler, N. N., Schwartzbaum, J. A., Jackson, B. M., Love, R. L., \& Harris, R. E. (2006). Comorbidity among the morbidly obese: a comparative study of 2002 US hospital patient discharges. Surgery for Obesity and Related Diseases, 2(2), 105111. http://dx.doi.org/10.1016/j.soard.2006.01.004. PMid:16925332.

Sharma, K., Ko, E. Y., Assefa, A. D., Ha, S., Nile, S. H., Lee, E. T., \& Park, S. W. (2015). Temperature-dependent studies on the total phenolics, flavonoids, antioxidant activities, and sugar content in six onion varieties. Journal of Food and Drug Analysis, 23(2), 243 252. http://dx.doi.org/10.1016/j.jfda.2014.10.005. PMid:28911379.

Simlat, M., Skrzypek, E., Warchoł, M., Maciaszek, I., \& Ptak, A. (2019). Evaluation on Stevia rebaudiana Bertoni seed germination and seedling development under phytohormones treatment. Scientia Horticulturae, 257, 108717. http://dx.doi.org/10.1016/j.scienta.2019.108717.

Szejtli, J., \& Szente, L. (2005). Elimination of bitter, disgusting tastes of drugs and foods by cyclodextrins. European Journal of Pharmaceutics and Biopharmaceutics, 61(3), 115-125. http://dx.doi.org/10.1016/j. ejpb.2005.05.006. PMid:16185857.

Soininen, T. H., Jukarainen, N., Auriola, S. O., Julkunen-Tiitto, R., Karjalainen, R., \& Vepsäläinen, J. J. (2014). Quantitative metabolite profiling of edible onion species by NMR and HPLC-MS. Food Chemistry, 165, 499-505. http://dx.doi.org/10.1016/j.foodchem.2014.05.132. PMid:25038704.

Suzuki, M., \& Cutcliffe, J. A. (1989). Fructans in onion bulbs in relation to storage life. Canadian Journal of Plant Science, 69(4), 1327-1333. http://dx.doi.org/10.4141/cjps89-160.

Van Handel, E. (1968). Direct microdetermination of sucrose. Analytical Biochemistry, 22(2), 280-283. http://dx.doi.org/10.1016/00032697(68)90317-5. PMid:5641848. 
Sasaki, M., \& Goto, M. (2008). Recovery of phenolic compounds through the decomposition of lignin in near and supercritical water. Chemical Engineering and Processing: Process Intensification, 47(9-10), 1609-1619. http://dx.doi. org/10.1016/j.cep.2007.09.001.

Wang, J., Sun, B., Cao, Y., Tian, Y., \& Li, X. (2008). Optimisation of ultrasound-assisted extraction of phenolic compounds from wheat bran. Food Chemistry, 106(2), 804-810. http://dx.doi.org/10.1016/j. foodchem.2007.06.062.
Yadav, S. K., \& Guleria, P. (2012). Steviol glycosides from Stevia: biosynthesis pathway review and their application in foods and medicine. Critical Reviews in Food Science and Nutrition, 52(11), 988-998. http://dx.doi. org/10.1080/10408398.2010.519447. PMid:22823347.

Yracheta, J. M., Lanaspa, M. A., Le, M. T., Abdelmalak, M. F., Alfonso, J., Sánchez-Lozada, L. G., \& Johnson, R. J. (2015). Diabetes and kidney disease in American Indians: potential role of sugar-sweetened beverages. Mayo Clinic Proceedings, 90(6), 813-823. http://dx.doi. org/10.1016/j.mayocp.2015.03.018. PMid:26046414. 


\section{Supplementary Material}

Supplementary material accompanies this paper.

Supplementary Figure 1. Principal component analysis (PCA) of sensory evaluation of onion and onion-stevia hot extracts with different stevia-to-onion ratios $(\mathrm{w} / \mathrm{w})$ and extraction temperatures. 105,115 , and 125 - extracted at $105^{\circ} \mathrm{C}, 115^{\circ} \mathrm{C}$, and $125^{\circ} \mathrm{C}$ for $4 \mathrm{~h}$, respectively. OHE: onion hot extract, OSHE1: onion-stevia leaves hot extract in stevia-to-onion ratio 1:100 (w/w), OSHE2: onion-stevia leaves hot extract in stevia-to-onion ratio 2:100 (w/w), OSHE3: onion-stevia leaves hot extract in stevia-to-onion ratio 3:100 (w/w). $(\mathrm{p}<0.05)$

This material is available as part of the online article from http://www.scielo.br/cta 